\title{
Factor VIII complex in uraemia and effects of haemodialysis
}

\author{
J H TURNEY, H F WOODS, M R FEWELL, M J WESTON
}

\begin{abstract}
Levels of the factor VIII complex were found to be raised in patients with chronic renal failure and further raised by regular dialysis. Increased fibrinogen concentrations were also found. These results suggest the existence of a prothrombotic state in uraemia that is exacerbated by haemodialysis. Ristocetin-induced platelet agglutination, however, was depressed in uraemia and worsened by dialysis. This defect may be transferred to normal platelets from dialysed uraemic plasma, suggesting the existence of an inhibitor of the interaction between factor VII and platelet glycoprotein.

These results may help to explain the anomaly of a prolonged bleeding time together with accelerated atherogenesis that is found in patients with uraemia receiving dialysis.
\end{abstract}

\section{Introduction}

Despite the central role of factor VIII in haemostasis its biology is not yet fully elucidated. ${ }^{1}$ It appears to be a complex consisting of factor VIII coagulant activity, factor VIII-related antigen, and factor VIII-von Willebrand factor (VIII vWf), which may be the same as the ristocetin cofactor. VIII $\mathrm{vWf}$ is antigenically related to factor VIII-related antigen, and may be a subunit of it that plays a part in ristocetin-induced platelet agglutination and the retention of platelets within glass-bead columns. ${ }^{2}$ Physiologically, VIII vWf appears to mediate the interaction between platelet-membrane glycoproteins and exposed collagen, and

\footnotetext{
King's College Hospital Renal Unit, Dulwich Hospital, London SE22 8PT

J H TURNEY, MA, MRCP, senior registrar

H F WOODS, MRCP, research registrar (present appointment: consultant nephrologist, Amiri Hospital, Kuwait)

M R FEWELL, FIMLS, senior technician (present address: department of haematology, St Helier Hospital, Carshalton)

M J WESTON, MD, MRCP, consultant physician
}

defects of VIII vWf may be shown by the prolongation of the capillary bleeding time and by decreased adhesion of platelets to exposed vascular endothelium. ${ }^{3}$

An apparent anomaly of the uraemic state is the association of a prolonged bleeding time with an increased risk of cardiovascular disease. The raised prostacyclin concentrations in uraemia 4 may contribute to the prolonged bleeding time but appear not to prevent the development of atherosclerosis. Studies of factor VIII in uraemia have yielded conflicting results, ${ }^{5-11}$ but most suggest raised concentrations with perhaps abnormal function of VIII $\mathrm{vWf} .^{5}$

We investigated the factor VIII complex in patients with chronic uraemia receiving and not receiving dialysis and present a hypothesis that may reconcile the haemorrhagic diathesis with the increased risk of cardiovascular disease in uraemia.

\section{Patients and methods}

We studied 81 patients on 221 occasions. Twenty-four patients had chronic renal failure due to various causes (serum creatinine concentration $>300 \mu \mathrm{mol} / 1(>3.4 \mathrm{mg} / 100 \mathrm{ml})$ ). Forty-one patients had stable end-stage renal failure and had been established on regular dialysis. A further 16 patients, with declining renal function, were studied before and after they were established on regular dialysis, and their results were included as appropriate in the chronic renal failure and regular dialysis groups. In addition, six patients were studied during routine haemodialysis with heparin anticoagulation and again during a subsequent dialysis with prostacyclin infusion. Heparin was administered as a $50 \mathrm{IU} / \mathrm{kg}$ intravenous bolus before dialysis plus a constant infusion of $30 \mathrm{IU} / \mathrm{kg} / \mathrm{h}$ for the first four hours of the five-hour dialysis. The same dose of the same batch of heparin was used for the subsequent study, but in addition prostacyclin (Wellcome Research Laboratories) $5 \mathrm{ng} / \mathrm{kg} / \mathrm{min}$ was infused via the dialyser inlet line throughout the dialysis. Arterial (dialyser inlet) blood samples were collected before and at 60 -minute intervals during dialysis.

Blood was collected into $3 \cdot 13 \%$ HEPES-citrate and centrifuged at $1200 \mathrm{~g}$ for 20 minutes at $4^{\circ} \mathrm{C}$ and the plasma stored at $-20^{\circ} \mathrm{C}$. Factor VIII-related antigen was measured by immunoelectrophoresis. ${ }^{12}$ Factor VIII coagulant activity was assayed by the two-stage method of Denson. ${ }^{13}$ Fibrinogen was measured by the polymerisation method of Clauss. ${ }^{14}$ Platelet-rich plasma for ristocetin-induced platelet agglutination was obtained from nine volumes of venous blood collected into one volume of $3.8 \%$ citrate and centrifuged at $150 \mathrm{~g}$ for 10 minutes at room 
temperature, to give a platelet count of $200-400 \times 10^{9} / 1$. The change in optical density per minute was determined using a Born aggregometer (Albert Browne Ltd) with ristocetin (Lundbeck) at a final concentration of $1.5 \mathrm{mg} / \mathrm{ml}$. In further studies ristocetin-induced aggregation was performed on unwashed normal platelets suspended at a final concentration of $200 \times 10^{9} / 1$ in platelet-poor plasma from patients with chronic uraemia or receiving regular dialysis. Aggregations were performed in duplicate with platelets from normal controls resuspended in their own plasma, the change in optical density so obtained being regarded as $100 \%$. Results were analysed using paired and unpaired $t$ tests and, when appropriate, the $\chi^{2}$ test with Yates's correction.

\section{Results}

Factor VIII - Values of factor VIII-related antigen and coagulant activity were significantly higher than control values in both the patients receiving dialysis and those with uraemia (table I), but the ratio of factor VIII-related antigen to coagulant activity was higher in the patients receiving dialysis, as was the number of patients with a ratio of over 1.5 . In those patients with chronic uraemia in whom serial samples were obtained until their establishment on regular dialysis (table II) there was a significant widening of the ratio, resulting mainly from lower values of factor VIII coagulant activity, consistent with increased consumption of this activity. Consequently, a

TABLE I-Mean $( \pm S D)$ values of factor VIII complex in patients with chronic renal failure and receiving dialysis compared with normal adult controls

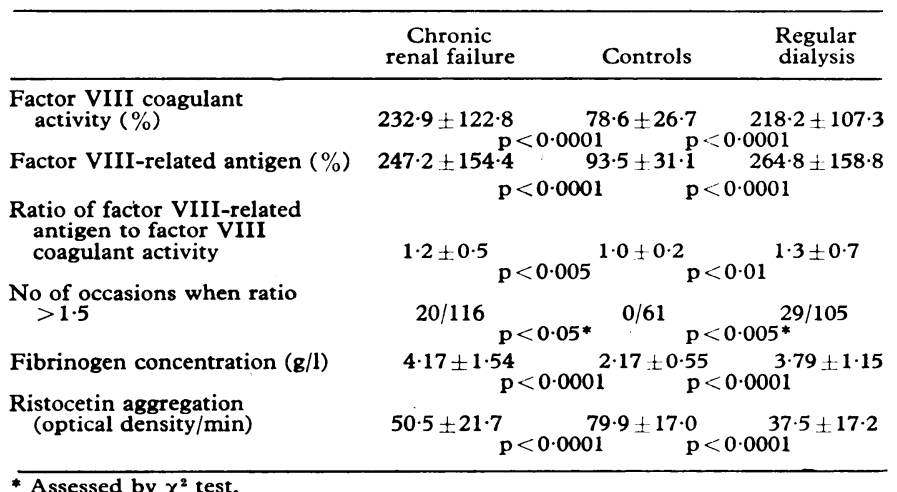

* Assessed by $x^{2}$ test.

TABLE II-Paired studies of factor VIII complex (mean $\pm S E M$ ) in 16 patients with chronic renal failure followed up sequentially until they were established on regular haemodialysis

\begin{tabular}{|c|c|c|}
\hline & $\begin{array}{l}\text { Chronic } \\
\text { renal failure }\end{array}$ & $\begin{array}{l}\text { Regular } \\
\text { dialysis }\end{array}$ \\
\hline Factor VIII coagulant activity ( $\%)$ & \multicolumn{2}{|c|}{ 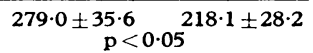 } \\
\hline Factor VIII-related antigen ( $\%)$ & \multicolumn{2}{|c|}{ NS 2101 IJTH } \\
\hline $\begin{array}{l}\text { Ratio of factor VIII-related antigen to factor } \\
\text { VIII coagulant activity }\end{array}$ & \multicolumn{2}{|c|}{$1 \cdot 0 \pm \underset{p}{0}<0.0005$} \\
\hline No of patients in whom ratio $>1.5$ & \multicolumn{2}{|c|}{${ }_{1 / 16^{p}}^{p<0.0005}$} \\
\hline Fibrinogen concentration $(\mathrm{g} / \mathrm{l})$ & $4.02 \pm 0.37$ & $3 \cdot 86 \pm 0 \cdot 22$ \\
\hline
\end{tabular}

* Assessed with $\chi^{2}$ test.

significantly greater number of patients had a ratio of over 1.5 after starting regular dialysis. The ratio in normal people is unity, and an increase indicates consumption of coagulant activity, thereby acting as a marker of intravascular coagulation. ${ }^{13}$

Factor VIII-related antigen during haemodialysis-During haemodialysis with heparin alone (table III) values of factor VIII-related antigen rose progressively to $131 \cdot 3 \pm$ SEM $7 \cdot 7 \%$ of the predialysis values. The additional infusion of prostacyclin, however, prevented this rise.

Ristocetin-induced platelet agglutination-Uraemic patients, whether or not treated by dialysis, had significantly depressed rates of platelet
TABLE III-Change in factor VIII-related antigen during haemodialysis with heparin and heparin plus prostacyclin expressed as mean $\pm S E M$ percentage of predialysis values (time $0=100 \%$ )

\begin{tabular}{|c|c|c|c|c|c|}
\hline & \multicolumn{5}{|c|}{ Duration of dialysis (min) } \\
\hline & 60 & 120 & 180 & 240 & 360 \\
\hline \multirow{4}{*}{$\begin{array}{l}\text { Dialysis with heparin } \\
\text { Significance of differenc } \\
\text { from time } 0 \\
\text { Dialysis with heparin } \\
\text { and prostacyclin } \\
\text { Significance of differenc } \\
\text { from time } 0\end{array}$} & $106 \cdot 3+4 \cdot 7$ & $113 \cdot 6 \pm 5 \cdot 4$ & $120 \cdot 8 \pm 6 \cdot 0$ & $123 \cdot 2 \pm 5 \cdot 2$ & $2131 \cdot 3 \pm 7 \cdot 7$ \\
\hline & NS & $p<0.01$ & $p<0.005$ & $\mathrm{p}<0.0025$ & $\mathrm{p}<0.001$ \\
\hline & $98 \cdot 2 \pm 1 \cdot 5$ & $101 \cdot 0+1.4$ & $101 \cdot 4+1.8$ & $102 \cdot 3+4 \cdot 7$ & $102 \cdot 2 \pm 2 \cdot 4$ \\
\hline & NS & NS & NS & NS & NS \\
\hline $\begin{array}{l}\text { Heparin } v \text { hepar } \\
\text { prostacyclin }\end{array}$ & NS & $p<0.05$ & $\mathrm{p}<0.01$ & $\mathrm{p}<0.01$ & $\mathrm{p}<0.01$ \\
\hline
\end{tabular}

aggregation by ristocetin (table I). Platelets from patients receiving dialysis, however, were significantly less reactive than those from patients with chronic uraemia not receiving dialysis $(p<0.001)$. In the ristocetin-aggregation cross-over study the addition of plasma from patients with chronic uraemia enhanced the aggregation of normal platelets $(120 \cdot 8 \pm S D 33.8 \%$ of control values, $p<0.005)$. Conversely, plasma from patients receiving dialysis inhibited the aggregation of normal platelets $(67.6 \pm 26.3 \%, \mathrm{p}<0.0001)$ when compared with aggregation in normal plasma. The difference in effect of plasma from the two patient groups was highly significant $(\mathrm{p}<0.0001)$.

Fibrinogen concentrations-Patients both receiving and not receiving dialysis had significantly raised fibrinogen concentrations, the values in the dialysis population being rather lower than the values in patients with chronic renal failure, perhaps resulting from repeated deposition of fibrin within the dialyser. In the serially sampled patients fibrinogen concentrations fell after establishment on regular dialysis but this difference was not statistically significant.

\section{Discussion}

Our results, obtained in the largest series so far reported, confirm and extend those of previous studies, ${ }^{5-11}$ which showed raised values of the factor VIII complex in chronic renal failure. Regular dialysis does not correct these abnormalities and worsens the disproportion between factor VIII-related antigen and VIII coagulant activity, indicating increased consumption of coagulation factors in patients receiving dialysis. ${ }^{13}$ There was, however, decreased platelet agglutination in response to the antibiotic ristocetin, which is a measure of at least one aspect of VIII vWf activity. ${ }^{2}$ Ristocetin-induced agglutination of dialysed uraemic platelets was further depressed, and plasma from patients receiving dialysis inhibited the response of normal platelets to ristocetin. These studies of the VIII-ristocetin cofactor are in broad agreement with those of Kazatchkine et $a l^{5}$ but disagree with those of other authors, ${ }^{6-11}$ who used different methods. The finding of normal or raised values of VIII vWf in these latter studies, however, does not necessarily imply normal function. ${ }^{15}$ Thus there is a disparity between quantity and function of some aspects of the VIII complex.

This is the first time a plasma inhibitor of ristocetin-induced aggregation has been found in renal disease, although similar inhibition has been described in other diseases such as leukaemia. ${ }^{16}$ The enhancement of the ristocetin effect on normal platelets by plasma from patients with chronic renal failure before the start of maintenance haemodialysis probably reflects the greater availability of factor VIII. But the paradoxical inhibition of ristocetin agglutination in the presence of raised factor VIII values in plasma from patients receiving dialysis suggests the presence of an inhibitor, the accumulation of which might be greater in functionally anephric patients receiving dialysis than in patients with chronic uraemia with residual renal function. Various uraemic toxins accumulate in patients receiving dialysis and are poorly cleared by routine dialysis. ${ }^{17}$ The decreased response to ristocetin by uraemic platelets in autologous plasma, which enhances agglutination of normal platelets, probably represents an intrinsic platelet defect. ${ }^{18}$ The further depression of agglutination of platelets from patients 
receiving dialysis is probably due to a combination of the intrinsic platelet defect with additional inhibition by the plasma. Unlike other aspects of platelet function, adhesion, which is a measure of VIII vWf activity, is not improved by dialysis. ${ }^{19}$

Raised factor VIII values indicate a prothrombotic state ${ }^{13}$ in which the normal balance between thrombosis and fibrinolysis is shifted towards a thrombotic tendency. When associated with increased concentrations of coagulation substrate (fibrinogen) and decreased concentrations of antithrombin III in uraemia ${ }^{20}$ they provide a state in which endothelial damage-for example,

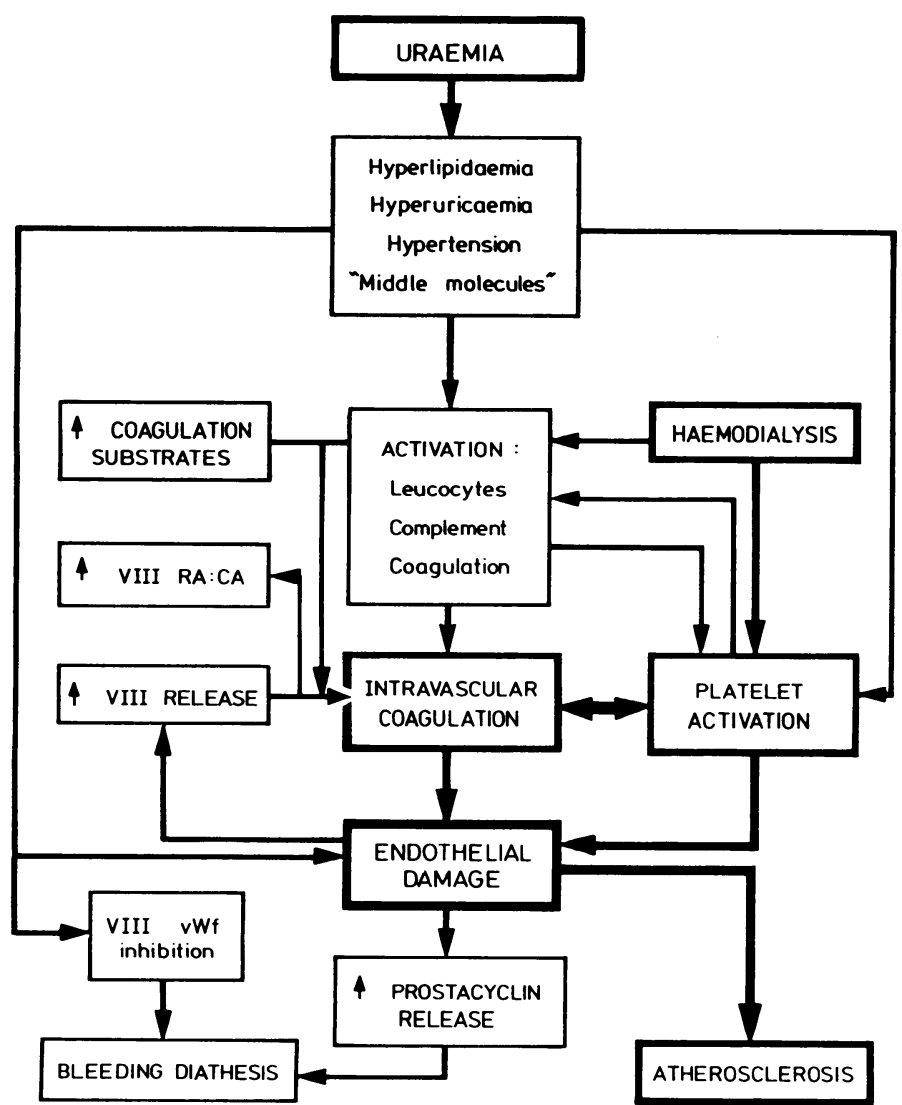

Schematic representation of the coagulopathy induced by chronic uraemia and its exacerbation by haemodialysis, which may result in the development of both atherosclerosis and uraemic bleeding diathesis.

VIII RA = Factor VIII-related antigen. VIII CA $=$ Factor VIII coagulant activity. VIII $\mathbf{v W f}=$ Factor VIII-von Willebrand factor.

by hypertension or hyperlipidaemia-may progress to atherosclerosis. ${ }^{21}$ That the factor VIII complex plays a part in mediating aterrial damage has been shown in animal experiments. ${ }^{22}$ Furthermore, the widened ratio of factor VIII-related antigen to VIII coagulant activity is a marker of intravascular coagulation, ${ }^{13}$ as has been shown, for example, in pre-eclampsia. ${ }^{23}$

We have previously shown that the potent antiplatelet agent prostacyclin not only prevents platelet activation and consumption during haemodialysis ${ }^{24}$ but also prevents the dialysisinduced rise in concentrations of antithrombin III that may result from release of antithrombin III from platelets and endothelium damaged by the extracorporeal circulation $(\mathrm{J} \mathrm{H}$ Turney et al, paper in preparation). The results presented here show that values of factor VIII-related antigen also rise progressively during dialysis with heparin alone and that this rise is also prevented by administering prostacyclin. As VIII-related antigen is synthesised by both vascular endothelium ${ }^{25}$ and megakaryocytes ${ }^{26}$ the raised values in uraemia may result from long-term, low-grade endothelial damage and platelet activation, which are exacerbated by the extracorporeal circulation. This contention is supported by the ratio of factor VIII-related antigen to coagulant activity, which is widened in chronic renal failure and to an even greater extent during regular dialysis. Thus a vicious circle is created, with raised values of factor VIII, a marker of endothelial damage, providing the mechanism for both further vascular insult and intravascular coagulation, the situation being exacerbated by the reinfusion during haemodialysis of activated platelets, etc (figure). This study provides further support for the use of platelet-suppressive treatment in haemodialysis. ${ }^{27}$

The increased concentrations of prostacyclin in uraemia may be the result of increased vascular synthesis ${ }^{4}$ resulting from sustained endothelial damage. The prostacyclin may provide some endothelial protection but, as a "trade-off", 28 results in a prolonged bleeding time. Prolonged bleeding time may also result from either a deficiency of VIII vWf, as in von Willebrand's disease, ${ }^{29}$ or a defect of the platelet-membrane glycoproteins as in Bernard-Soulier disease. ${ }^{30}$ 31 Our results suggest that uraemic platelets have a Bernard-Soulier-type defect of ristocetininduced agglutination in the presence of raised values of factor VIII, which can enhance the aggregation of normal platelets. In addition, there is a plasma inhibitor of the VIII vWf-platelet interaction in patients receiving dialysis, which we suggest is one or more of the uraemic "middle-molecule" toxins. The bleeding time in uraemic patients may be shortened by infusing cryoprecipitate, ${ }^{32}$ but, unlike in von Willebrand's disease, the improvement takes some hours to appear and is relatively short lived. The time course of the effect of cryoprecipitate is compatible with competition for the platelet glycoprotein 1Breceptor site between VIII vWf in cryoprecipitate and the abnormal uraemic VIII vWf or with a plasmatic factor that may alter the nature of or combine with, and therefore occlude, the receptor. The result of this defect of VIII vWf-mediated platelet adhesion is the characteristic uraemic bleeding diathesisnamely, decreased ristocetin-induced agglutination and platelet retention in glass-bead columns, and a prolonged bleeding time. As with Bernard-Soulier platelets, however, this defect does not necessarily affect the aggregation (as opposed to adhesion) of platelets to various stimuli including collagen, adenosine diphosphate, and thrombin.

The hypothesis derived from our studies of factor VIII in uraemia permits the reconciliation of uraemic bleeding with the reported accelerated atherogenesis in patients receiving dialysis. ${ }^{33}$ The prothrombotic state induced by uraemia and aggravated by dialysis results from and continues to exacerbate endothelial damage, the consequence of which may be atherosclerosis. Prostacyclin released in response to the endothelial damage may prolong the capillary bleeding time, which is also increased by an acquired defect in function of the factor VIII vWf.

Reprint requests should be addressed to $\mathrm{Dr} M \mathrm{~J}$ Weston, Renal Unit, Dulwich Hospital, East Dulwich Grove, London SE22 8PT.

\section{References}

${ }^{1}$ Bloom AL, Peake IR. Factor VIII and its inherited disorders. Br Med Bull $1977 ; 33: 219-24$

2 Weiss HJ, Hoyer LW, Rickles FR, Varma A, Rogers J. Quantitative assay of a plasma factor deficient in von Willebrand's disease that is necessary for platelet aggregation. $\mathcal{f}$ Clin Invest 1973;52:2708-16.

${ }^{3}$ Sakariassen KS, Bolhuis PA, Sixma JJ. Human blood platelet adhesion to artery subendothelium is mediated by factor VIII-von Willebrand factor bound to the subendothelium. Nature 1979;276:636-8.

${ }^{4}$ Remuzzi G, Marchesi D, Cavenaghi AE, et al. Bleeding in renal failure: a possible role of vascular prostacyclin $\left(\mathrm{PGI}_{2}\right)$. Clin Nephrol 1979;12: 127-31.

${ }^{5}$ Kazatchkine M, Sultan Y, Caen JP, Hurst PE. Bleeding in renal failure: a possible cause. $\mathrm{Br}$ Med $\mathcal{f} 1976$;ii:612-5.

${ }^{6}$ Ruggeri ZM, Ponticelli C, Mannucci PM. Factor VIII and chronic renal failure. Br Med F $1977 ; \mathrm{i}: 1085$.

${ }^{7}$ Herrmann RP, Marshall LR, Hurst PE. Bleeding in renal failure: a possible cause. $\mathrm{Br} \operatorname{Med} \mathcal{F} 1977 ; \mathrm{i}: 1601$. 
${ }^{8}$ Remuzzi G, Livio M, Roncaglioni MC, Mecca G, Donati MB, de Gaetano G. Bleeding in renal failure: is von Willebrand factor implicated ? $\mathrm{Br}$ Med f 1977;ii:359-61.

${ }^{9}$ Remuzzi G, Bertani T, Mecca G, Donati MB, de Gaetano G. Factor VIII-related protein on vascular intima of patients with chronic renal failure and prolonged bleeding times. $B r \operatorname{Med} F$ 1978; :70-2.

10 Warrell RP, Hultin MB, Coller BS. Increased factor VIII/von Willebrand factor antigen and von Willebrand factor activity in renal failure. $A m \mathcal{F}$ Med $1979 ; 66: 226-8$

11 Ruggeri ZM. Endothelium, factor VIII/von Willebrand factor, and renal diseases. In: Remuzzi G, Mecca G, de Gaetano G, eds. Hemostasis, prostaglandins, and renal disease. New York: Raven Press, 1980:11-20.

12 Laurell C-B. Electroimmuno assay. Scand $\mathcal{F}$ Clin Lab Invest $1972 ; 29$, suppl 124:21-37.

${ }^{13}$ Denson KWE. The ratio of factor VIII-related antigen and factor VIII biological activity as an index of hypercoagulability and intravascular coagulation. Thromb Res 1977;10:107-19.

14 Clauss A. Gerinnungsphysiologische Schnellmethode zur Bestimmung des Fibrinogens. Acta Haematol (Basel) 1957;17:237-46.

16 Bloom AL. Factor VIII-related protein in renal failure with prolonged bleeding time. Br Med f 1978;i:306.

16 Wautier JL, Nurden AT, Michel H, Caen JP. Defective ristocetin aggregation not attributable to a von Willebrand or Bernard-Soulier type defect. Thromb Haemostas $1977 ; 38: 4$.

17 Gotch FA. A quantitative evaluation of small and middle molecule toxicity in the therapy of uraemia. Dialysis and Transplantation 1980;9:183-94.

18 Lindsay RM, Moorthy AV, Koens F, Linton AL. Platelet function in dialyzed and non-dialyzed patients with chronic renal failure. Clin Nephrol $1975 ; 4: 52-7$.

19 Remuzzi G, Livio M, Marchario G, Mecca G, de Gaetano G. Bleeding in renal failure: altered platelet function in chronic uraemia only partially corrected by haemodialysis. Nephron $1978 ; 22: 347-53$

20 Turney JH, Woods HF, Weston MJ. Regular haemodialysis therapy induces a prothrombotic state. Thromb Haemostas 1979;42:67.

${ }^{21}$ Ross R, Glomset JA. The pathogenesis of atherosclerosis. $N$ Engl f Med $1976 ; 295: 369-77,420-25$.
${ }^{22}$ Fuster V, Bowie EJW, Lewis JC, Fass DN, Owen CA, Brown CL. Resistance to arteriosclerosis in pigs with von Willebrand's disease. $\mathcal{F}$ Clin Invest $1978 ; 61: 722-30$.

${ }^{23}$ Redman CWG, Denson KWE, Beilin LJ, Bolton FG, Stirrat GM. Factor VIII consumption in pre-eclampsia. Lancet 1977;ii:1249-52.

24 Turney JH, Williams LC, Fewell MR, Parsons V, Weston MJ. Platelet protection and heparin sparing with prostacyclin during regular dialysis $\widehat{\triangle}$ therapy. Lancet $1980 ;$ ii :219-22.

${ }^{25} \mathrm{Jaffe}$ EA. Endothelial cells and the biology of factor VIII. $N$ Engl $\mathcal{F}$ Med 1977:296:377-83.

${ }^{26}$ Nachman R, Levine R, Jaffe EA. Synthesis of factor VIII antigen by $\mathbb{D}$ cultured guinea pig megakaryocytes. $\mathcal{F}$ Clin Invest 1977;60:914-21.

27 Weston MJ, Woods HF, Turney JH. Antiplatelet agents and extracorporeal $\varrho$ circulation. Int $\mathcal{F}$ Artif Organs $1980 ; 3: 129-32$.

${ }^{28}$ Bricker NS. On the pathogenesis of the uremic state: an exposition of the "trade-off"' hypothesis. N Engl I Med 1972;286:1093-9.

${ }^{29}$ Mannucci PM, Pareti FI, Holmberg L, Nilsson IM, Ruggeri ZM. Studies on the prolonged bleeding time in von Willebrand's disease. $\mathcal{F}$ Lab Clin Med 1976;88:662-71.

30 Weiss HJ, Tschopp TB, Baumgartner HR, Sussmann II, Johnson MM, Egan JJ. Decreased adhesion of giant (Bernard-Soulier) platelets to subendothelium. Further implications on the role of the von Willebrand factor in hemostasis. Am $\mathcal{F}$ Med 1974 ;57:920-5.

31 Jenkins CSP, Phillips DR, Clemetson KJ, Meyer O, Larrier MJ, Luscher $\vec{\circ}$ EF. Platelet-membrane glycoproteins implicated in ristocetin-induced aggregation. Studies of the proteins of platelets from patients with $\omega$ Bernard-Soulier syndrome and von Willebrand's disease. 7 Clin Invest 1976;57:112-24

32 Janson PA, Jubelirer SJ, Weinstein MJ, Deykin D. Treatment of the bleeding tendency in uremia with cryoprecipitate. $N$ Engl $f$ Med $1980 ; 303: 1318-22$.

${ }^{33}$ Lindner A, Charra B, Sherrard DJ, Scribner BH. Accelerated atherosclerosis in prolonged maintenance haemodialysis. N Engl f Med 1974; 290 :697-701.

(Accepted 2 April 1981)

\title{
Metabolic studies in unaffected co-twins of non-insulin-dependent diabetics
}

\author{
A H BARNETT, A J SPILIOPOULOS, D A PYKE, W A STUBBS, J BURRIN, K G M M ALBERTI
}

\begin{abstract}
Forty-eight out of 53 non-insulin-dependent diabetic identical twin pairs were concordant for diabetes. In the five discordant pairs the diabetic twin had only recently been diagnosed. Oral glucose tolerance tests were carried out on the unaffected twins of the five pairs and on matched controls. Fasting concentrations of blood glucose $(5.5 \pm 0.6$ v $3.7 \pm 0.3 \mathrm{mmol} / \mathbf{1} ; 99 \cdot 1 \pm 10.8$ v $66.6 \pm 5.4$ $\mathrm{mg} / 100 \mathrm{ml}$ ), haemoglobin $A_{1}$ (mean $9 \cdot 1 \%$, range $8 \cdot 8-9 \cdot 2 \%$ v mean $7 \cdot 9 \%$, range $7 \cdot 4-8 \cdot 4 \%$, lactate, alanine, and glycerol $(0.090 \pm 0.017 \mathrm{v} 0.045 \pm 0.008 \mathrm{mmol} / \mathrm{l})$; and the lactate: pyruvate ratio were significantly higher in the
\end{abstract}

Diabetic Department, King's College Hospital, London SE5 9RS

A H BARNETT, MD, MRCP, research fellow

A J SPILIOPOULOS, MD, research fellow

D A PYKE, MD, FRCP, consultant physician

Department of Medicine, St Bartholomew's Hospital, London EC1A 7BE

W A STUBBS, PHD, MRCP, lecturer in medicine

Department of Clinical Biochemistry and Metabolic Medicine, Royal Victoria Infirmary, Newcastle upon Tyne NE1 4LP

J BURRIN, PHD, research fellow

K G M M ALBERTI, DPHIL, FRCP, professor of clinical biochemistry twins than controls. After glucose challenge blood glucose, lactate, alanine, and glycerol concentrations and lactate: pyruvate ratio were increased in the twins. Insulin response was severely impaired, being almost absent in four of the five twins.

The non-diabetic members of the discordant noninsulin-dependent diabetic pairs showed noticeable metabolic abnormalities which would later presumably deteriorate to frank diabetes. These findings, taken with the high concordance rate for non-insulin-dependent diabetic twins, suggest that non-insulin-dependent diabetes is predominantly, possibly entirely, inherited.

\section{Introduction}

Over the past 14 years we have studied identical twin pairs in $\stackrel{0}{\overparen{D}}$ whom one or both were diabetic. Of the 200 pairs seen to date, $\stackrel{?}{+}$ 147 were insulin-dependent and 53 non-insulin-dependent 0 diabetics. Of the 53 non-insulin-dependent pairs, all but five were concordant - that is, both twins were diabetic; in contrast, \& among the insulin-dependent pairs only about half were $\stackrel{\mathbb{Q}}{\varrho}$ concordant. In the five discordant non-insulin-dependent pairs the diabetic twin had been diagnosed only within the past three years, whereas the interval between diagnosis of diabetes in the first and second twins of the 48 concordant pairs in no case exceeded seven years. Hence it seemed likely that the five so 